\title{
Analisis Variasi Busi Terhadap Performa dan Bahan Bakar Motor Bensin 2 Langkah Yamaha F1ZR 110CC
}

\section{Analysis of Spark Plug Variations on Performance and Fuel for Yamaha F1ZR 110CC 2-stroke Gasoline Motorcycles}

\author{
M. Bagus Anggoro', Armila2*, Rudi Kurniawan Arief ${ }^{2}$ \\ ${ }_{1,2^{*}, 3}$ Program Studi Teknik Mesin, Fakultas Teknik, Universitas Muhammadiyah Sumatera Barat \\ $1,2^{*}, 3 \mathrm{Jl}$. By Pass Aur Kuning No. 1 Bukittinggi, 26111 Indonesia \\ *Koresponden Email: armila.umsb.ac.id
}

Artikel dikirim: 09/09/2021

Artikel direvisi: 15/10/2021

Artikel diterima: 26/10/2021

\begin{abstract}
Abstrak. Busi memiliki berbagai jenis dan spesifikasi yang dapat meningkatkan performa sepeda motor. Tujuan dari penelitian ini adalah untuk mengetahui perbandingan torsi, daya, dan konsumsi bahan bakar pada mesin bensin dua langkah yang dihasilkan dari busi standar, platina, dan iridium. Metode yang digunakan dalam penelitian ini adalah dengan menggunakan metode uji varians satu arah atau One-way ANOVA. pengujian ini dilakukan dengan menggunakan sepeda motor yamaha F1ZR yang dilakukan dengan menggunakan alat uji dyno test. Hasil pengujian busi platinum ini memiliki torsi tertinggi mencapai $14,78 \mathrm{ft}$-lbs pada putaran mesin 7.500 rpm, sedangkan untuk busi standar diperoleh $10,14 \mathrm{ft}-\mathrm{lbs}$. pada putaran mesin $7500 \mathrm{rpm}$ dan busi iridium mendapatkan 9,53 ft-lbs pada putaran mesin $7500 \mathrm{rpm}$. Tenaga tertinggi didapatkan pada busi platinum mencapai $14,78 \mathrm{hp}$ pada putaran mesin $7500 \mathrm{rpm}$, sedangkan untuk busi standar 14,47 hp pada putaran mesin $7500 \mathrm{rpm}$ dan untuk busi iridium 13,62 hp pada putaran mesin $7500 \mathrm{rpm}$. Konsumsi bahan bakar terendah dihasilkan pada busi iridium yang mencapai $0,545 \mathrm{~kg} / \mathrm{jam}$ pada putaran mesin $5000 \mathrm{rpm}$, sedangkan konsumsi bahan bakar tertinggi pada busi platinum mencapai $0,700 \mathrm{~kg} / \mathrm{jam}$ pada putaran mesin $9000 \mathrm{rpm}$.
\end{abstract}

Keywords: Busi standar, Busi Platinum, Busi Iridium, Torsi, Daya

Abstract. Spark plugs have various types and specifications that can improve motorcycle performance. The purpose of this study was to determine the ratio of torque, power, and fuel consumption in a two-stroke gasoline engine produced from standard, platinum, and iridium spark plugs. The method used in this research is to use the one-way variance test method or One-way ANOVA. This test was carried out using a Yamaha FIZR motorcycle which was carried out using a dyno test tool. The test results for this platinum spark plug have the highest torque reaching $14.78 \mathrm{ft}$-lbs at 7,500 rpm engine speed, while for standard spark plugs obtained 10.14 ft-lbs. at $7500 \mathrm{rpm}$ engine speed and iridium spark plugs get $9.53 \mathrm{ft}$-lbs at $7500 \mathrm{rpm}$ engine speed. The highest power is obtained on platinum spark plugs reaching $14.78 \mathrm{hp}$ at $7500 \mathrm{rpm}$ engine speed, while for standard spark plugs $14.47 \mathrm{hp}$ at $7500 \mathrm{rpm}$ engine speed and for iridium spark plug $13.62 \mathrm{hp}$ at $7500 \mathrm{rpm}$ engine speed. The lowest fuel consumption is produced on iridium spark plugs which reaches $0.545 \mathrm{~kg} / \mathrm{hour}$ at $5000 \mathrm{rpm}$ engine speed, while the highest fuel consumption on platinum spark plugs reaches $0.700 \mathrm{~kg} / \mathrm{hour}$ at $9000 \mathrm{rpm}$ engine speed.

Keywords: Standard Spark Plug, Platinum Spark Plug, Iridium Spark Plug, Torque, Power

\section{PENDAHULUAN}

Busi adalah salah satu sparepart yang dipasang di mesin pembakaran dalam menggunakan ujung elektrode pada ruang bakar[1]. Untuk mencapai proses pembakaran pada busi ada sistem yang mempunyai kedudukan sangat berarti dalam sistem pengapian. Sistem pengapian yakni salah satu sistem yang ada dalam motor bensin agar motor mampu bekerja[2]. Sistem pengapian ini berguna untuk memunculkan bunga api dengan menggunakan koil pengapian (ignition coil), setelah itu JTTM: Jurnal Terapan Teknik Mesin is licensed under a Creative Commons Attribution-NonCommercial 4.0 International License.. 
Analisis Variasi Busi Terhadap Performa dan Bahan Bakar Motor Bensin 2 Langkah Yamaha F1ZR 110CC

didistribusikan ke busi lewat kabel tegangan besar untuk membakar kombinasi bahan bakar yang sudah dikompresi di dalam silinder[3][4]. Pada proses pembakaran di motor bakar, bahan bakar dan udara tercampur di dalam ruang bakar. Busi digunakan buat memercikan bunga api[5].

Besar kecilnya percikan bunga api busi sangat menentukan mutu pengapian serta pembakaran yang dihasilkan[6]. Pengapian yang maksimal bisa meningkatkan kinerja motor bakar[4]. Dengan didukung juga oleh mutu bahan, kualitas komponen yang dipergunakan, serta saat pengapian yang sesuai saat terbentuknya proses pembakaran[7] kinerja akan menjadi bagus.

Masing masing jenis busi mempunyai karakteristik percikan serta warna bunga api yang tidak sama[8]. Hasil pengujian yang dilakukan memberikan bahwa pemakaian busi bermassa tiga bisa menaikkan kemampuan mesin dibandingkan busi standar[5]. Di putaran $4000 \mathrm{rpm}$ torsi yang didapatkan bermassa tiga 10,29 Nm lebih besar dibandingkan busi standar $8.82 \mathrm{Nm}$ [4]. Daya poros yang dihasilkan pula lebih besar 4,3 kW dibandingkan busi standar $3.7 \mathrm{~kW}$. Konsumsi bahan bakar $0.22 \mathrm{~kg} / \mathrm{jam}$ lebih irit dari busi standar $0.26 \mathrm{~kg} / \mathrm{jam}[6]$. Tujuan penelitian ini dilakukan untuk mengetahui perbandingan torsi, daya, dan konsumsi bahan bakar di motor bensin dua langkah yang dihasilkan dari busi standar[9][10], platinum dan iridium. pengujian ini dilakukan menggunakan sepeda motor Yamaha F1ZR yang dilakukan memakai alat uji dynotest[11].

\section{METODE.}

2.1 Alat dan bahan yang digunakan selama penelitian.
a) Kunci busi,
b) Dynotest,
c) Stopwatch,
d) Gelas ukur,
e) Motor Yamaha F1ZR 110cc,
f) Busi standart,
g) Busi Platinum,
h) Busi Iridium

\subsection{Langkah-langkah penelitian}

Pada proses percobaan serta pengambilan data, maka perlu melakukan persiapan diantaranya:
a) Mempersiapkan alat dan bahan yang akan dipergunakan pada penelitian.
b) Letakkan motor diatas dynotest.
c) Ganti busi yang akan diteliti.
d) Menghidupkan mesin motor.
e) Masukkan gigi persneling.
f) Putaran mesin dinaikkan dengan memutar throttle secara cepat hingga putaran mesin maksimal.
g) waktu pengambilan data konsumsi bahan bakar tuangkan pertalite di buret. 
h) Ketika bahan bakar di buret menunjukkan angka nol (0) maka stopwatch mulai dihidupkan buat mengukur waktu konsumsi bahan bakar.

i) Catat waktu konsumsi bahan bakar dengan cara menghentikan stopwatch pada waktu putaran mesin tersebut menghabiskan bahan bakar $10 \mathrm{ml}$.

Akhiri percobaan ini dengan menurunkan putaran mesin secara perlahan serta kemudian dimatikan

2.3 Diagram alir penelitian

Dari alir penelitian ini proses pengujian busi untuk menentukan performa setiap busi yang dipergunakan dan setiap langkah yang dilakukan harus terukur dan terstruktur.

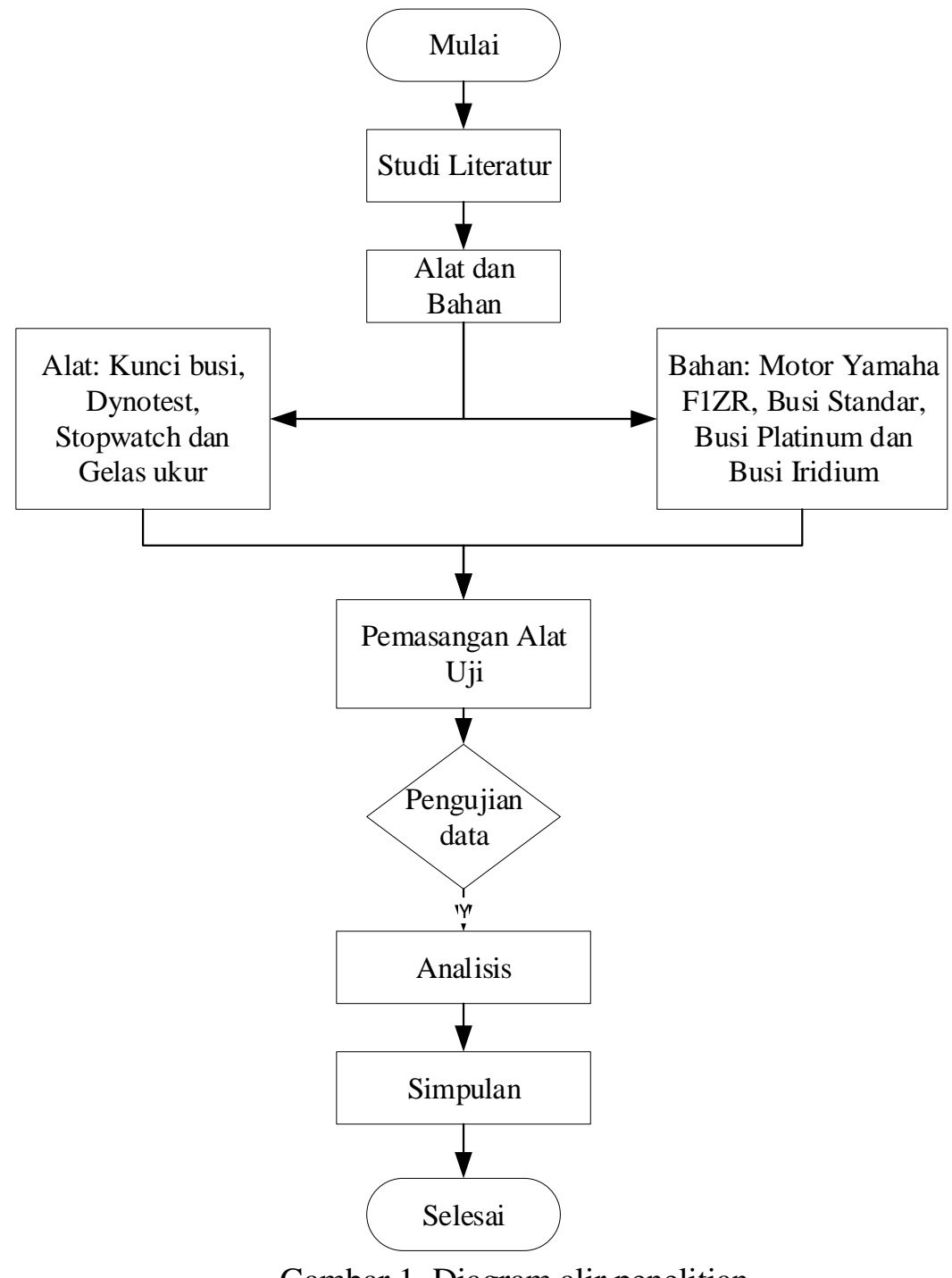

Gambar 1. Diagram alir penelitian

\section{HASIL DAN PEMBAHASAN.}

\subsection{Analisis torsi}

Pada percobaan torsi didapat dengan menggunakan data yang diperoleh dari pengujian dynotest[12]. Di dynotest data ditampilkan pada gambar 2 sebagai hasil, sehingga peneliti menarik data kembali dari hasil yang didapat dari pengujian. 
M. Bagus Anggoro, Armila, Rudi Kurniawan Arief

Analisis Variasi Busi Terhadap Performa dan Bahan Bakar Motor Bensin 2 Langkah

Yamaha F1ZR 110CC

Tabel 1. Pengujian torsi

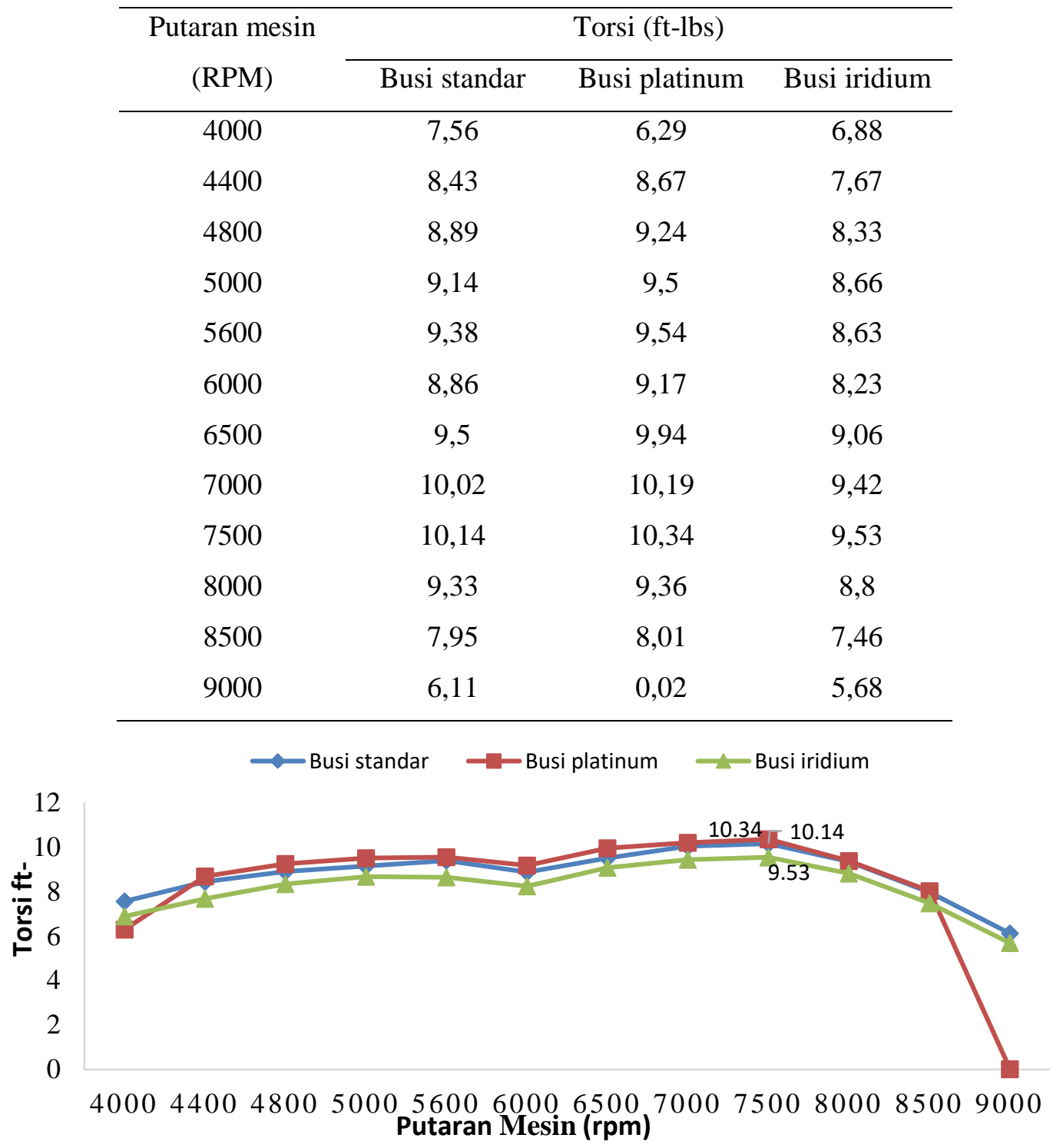

Gambar 2. Grafik hubungan torsi terhadap rpm

Dari grafik pada gambar 2, terlihat bahwa busi standar didapatkan torsi tertinggi yang mencapai 10,14 ft-lbs pada putaran $7500 \mathrm{rpm}$. Sedangkan pada busi platinum torsi tertinggi 10,34 ft-lbs pada putaran $7500 \mathrm{rpm}$ dan busi iridium torsi tertinggi 9,53 ft-lbs pada putaran $7500 \mathrm{rpm}[13]$.

\subsection{Analisis daya}

Dari hasil pengolahan data dalam pengujian diperoleh daya sesuai tabel 2:

Tabel 2. Pengujian daya

\begin{tabular}{cccc}
\hline \multirow{2}{*}{$\begin{array}{c}\text { Putaran mesin } \\
(\mathrm{RPM})\end{array}$} & \multicolumn{3}{c}{ Daya (HP) } \\
\cline { 2 - 4 } & Busi standar & Busi platinum & Busi iridium \\
\hline 4000 & 5,75 & 4,8 & 5,24
\end{tabular}




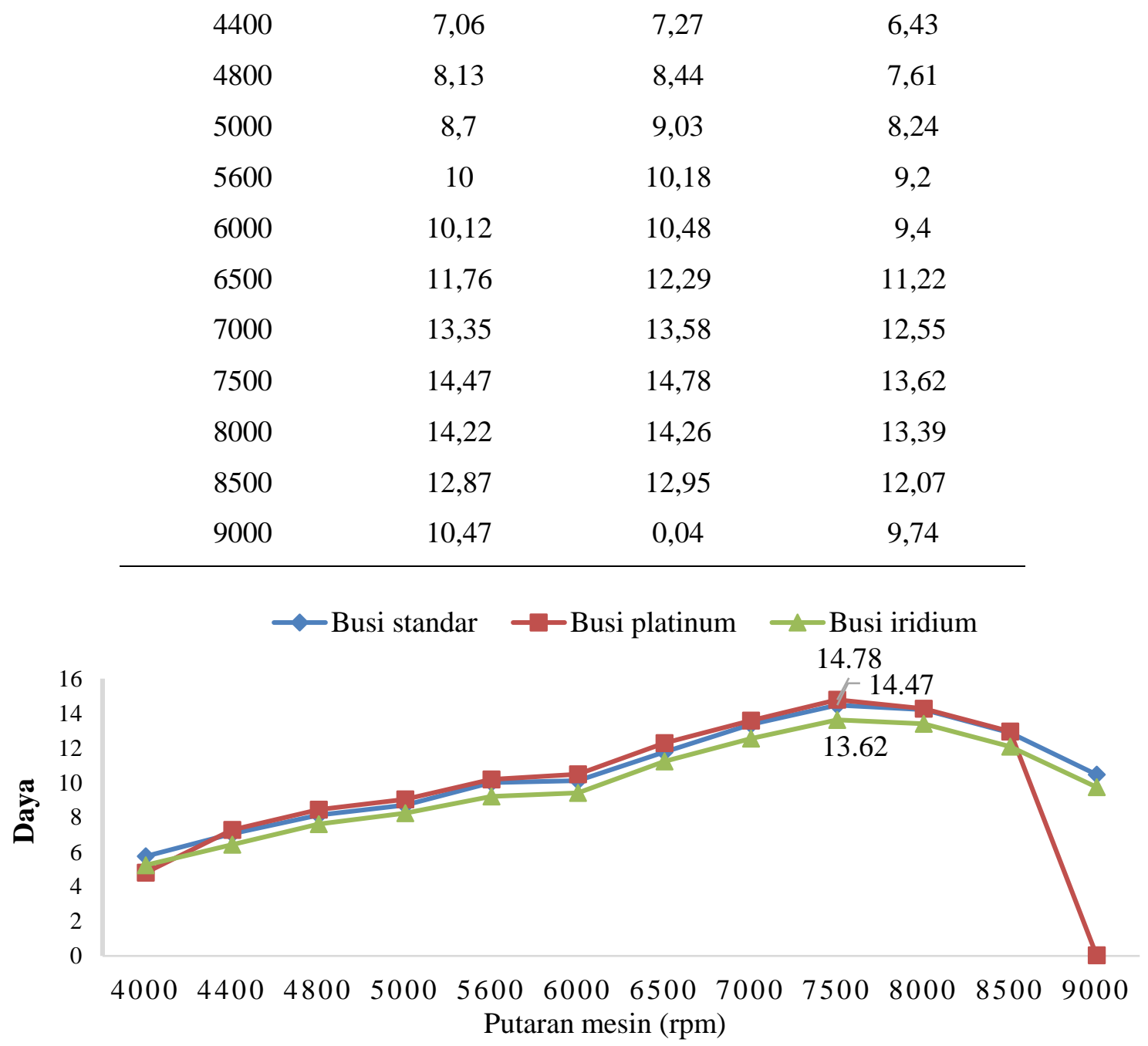

Gambar 3. Grafik hubungan daya terhadap rpm

Dari grafik pada gambar 3 busi standar didapatkan daya tertinggi yang mencapai 14,47 Hp dihasilkan pada putaran $7500 \mathrm{rpm}$. pada busi platinum daya tertinggi 14,78 Hp dihasilkan pada putaran $7500 \mathrm{rpm}$ dan busi iridium daya tertinggi 13,62 Hp dihasilkan pada putaran $7500 \mathrm{rpm}$.

\subsection{Analisis konsumsi bahan bakar}

Hasil pengolahan data dari pengukuran konsumsi bahan bakar didapat data sebagai berikut:

Tabel 3. Pengujian konsumsi bahan bakar

\begin{tabular}{ccccc}
\hline \multirow{2}{*}{$\begin{array}{c}\text { Putaran mesin } \\
(\mathrm{RPM})\end{array}$} & \multicolumn{4}{c}{ Konsumsi bahan bakar (kg/jam) } \\
\cline { 2 - 5 } & Busi standar & Busi platinum & Busi iridium & Bahan bakar 10 ml \\
\hline 5000 & 0,565 & 0,569 & 0,545 & 10 \\
6000 & 0,577 & 0,605 & 0,570 & 10 \\
7000 & 0.592 & 0,632 & 0,602 & 10 \\
8000 & 0,632 & 0,699 & 0,635 & 10 \\
9000 & 0,684 & 0,700 & 0,675 & 10 \\
\hline
\end{tabular}


Analisis Variasi Busi Terhadap Performa dan Bahan Bakar Motor Bensin 2 Langkah

Yamaha F1ZR 110CC

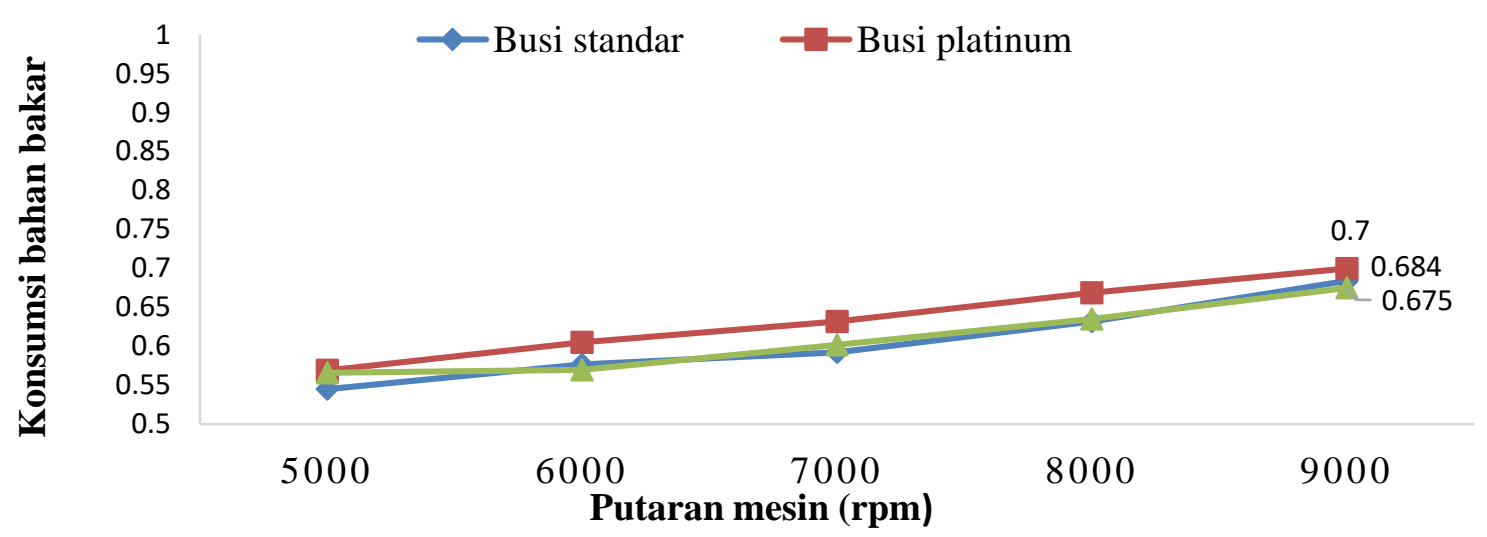

Gambar 4. Grafik hubungan konsumsi bahan bakar terhadap rpm[14].

Dari grafik pada gambar 4 konsumsi bahan bakar pada busi standar didapatkan konsumsi bahan bakar tertinggi[15] mencapai 0,684 kg/jam. pada busi platinum konsumsi bahan bakar tertinggi mencapai $0,700 \mathrm{~kg} / \mathrm{jam}$ dan busi iridium konsumsi bahan bakar tertinggi $0,675 \mathrm{~kg} / \mathrm{jam}$.

\section{SIMPULAN}

Torsi tertinggi didapatkan di busi platinum yang mencapai $14,78 \mathrm{ft}-\mathrm{lbs}$ pada putaran mesin 7500 rpm, sedangkan untuk busi standar dihasilkan 10,14 ft-lbs pada putaran mesin $7500 \mathrm{rpm}$ serta busi iridium 9,53 ft-lbs di putaran mesin $7500 \mathrm{rpm}$. Daya tertinggi dihasilkan pada busi platinum mencapai 14,78 Hp pada putaran mesin $7500 \mathrm{rpm}$, sedangkan untuk busi standar 14,47 Hp pada putaran mesin $7500 \mathrm{rpm}$ dan untuk busi iridium 13,62 Hp pada putaran mesin $7500 \mathrm{rpm}$. Konsumsi bahan bakar terendah didapatkan pada busi iridium yang mencapai $0,545 \mathrm{~kg} / \mathrm{jam}$ pada putaran mesin $5000 \mathrm{rpm}$, sedangkan konsumsi bahan bakar tertinggi didapatkan pada busi platinum mencapai $0,700 \mathrm{~kg} / \mathrm{jam}$ pada putaran mesin $9000 \mathrm{rpm}$.

\section{REFERENSI}

[1] M. Zaini and B. Indrawan, "Analisis pengendalian persediaan raw material spark plugs pada PT Denso Indonesia Jakarta Tahun 2014," J. Manaj. Bisnis Transp. Dan Logistik, vol. 3, no. 1, 2016.

[2] T. Cerri, G. D'Errico, and A. Onorati, "Experimental investigations on high octane number gasoline formulations for internal combustion engines," Fuel, vol. 111. 2013, doi: 10.1016/j.fuel.2013.03.065.

[3] E. B. Fiandry, U. M. Yogyakarta, J. Lingkar, S. Tamantirto, and D. I. Yogyakarta, "Pengaruh Penggunaan Variasi 3 Jenis Busi Terhadap Karakteristik Percikan Bunga Api Dan Kinerja Motor Honda Blade 110 Cc Berbahan Bakar Premium Dan Pertamax 95," J. Tek. Mesin UMY, 2015. 
[4] I. K. Suka Arimbawa, I. N. Pasek Nugraha, and K. R. Dantes, "ANALISIS PENGARUH CAMPURAN BAHAN BAKAR PERTALITE DENGAN NAPHTHALENE TERHADAP KONSUMSI BAHAN BAKAR, TORSI DAN DAYA PADA SEPEDA MOTOR 4 LANGKAH," J. Pendidik. Tek. Mesin Undiksha, vol. 7, no. 1, 2019, doi: 10.23887/jjtm.v7i1.18616.

[5] W. T. Putra and S. Sudarno, "Pengaruh Jenis Busi Terhadap Konsumsi Bahan Bakar Dan Emisi Gas Buang Pada Sepeda Motor Honda Revo Fit 110 cc," Turbo J. Progr. Stud. Tek. Mesin, vol. 5, no. 2, 2017, doi: 10.24127/trb.v5i2.503.

[6] A. Syahrifudin, D. Teguh Santoso, and V. Naubnome, "Pengaruh Variasi Busi Terhadap Performa dan Emisi Gas Buang pada Sepeda Motor," J. METTEK, vol. 6, no. 2, 2020, doi: 10.24843/mettek.2020.v06.i02.p04.

[7] Irpan Setiawan and Wilarso, "ANALISIS PERBANDINGAN TEKANAN TIPE POMPA BAHAN BAKAR INJEKSI DAN TIPE BAHAN BAKAR MEKANIK," TEKNOSAINS $J$. Sains, Teknol. dan Inform., vol. 8, no. 1, 2021, doi: 10.37373/tekno.v8i1.73.

[8] I. Dewa, K. Muku, I. Gusti, and K. Sukadana, "Pengaruh Rasio Kompresi terhadap Unjuk Kerja Mesin Empat Langkah Menggunakan Arak Bali sebagai Bahan Bakar," J. Ilm. Tek. Mesin CakraM, vol. 3, no. 1, 2009.

[9] Fahrisal, "Pembuatan Alat Uji Prestasi Mesin Motor Bakar Bensin Yamaha Lexam 115 Cc," Pembuat Alat Uji Present. Mesin Mot. Bakar Bensin Yamaha Lexam 115Cc, no. tas, 2017.

[10] S. Mulyono, G. Gunawan, and B. Maryanti, "Pengaruh Penggunaan dan Perhitungan Efisiensi Bahan Bakar Premium dan Pertamax Terhadap Unjuk Kerja Motor Bakar Bensin,” JTT (Jurnal Teknol. Terpadu), vol. 2, no. 1, pp. 28-35, 2014, doi: 10.32487/jtt.v2i1.38.

[11] N. A. Ryanto, N. A. Wigraha, and K. R. Dantes, "Pengaruh Pemotongan Permukaan Penutup Ruang Bakar Pada Kepala Silinder Terhadap Daya Dan Torsi Pada Motor Jupiter Z," J. Pendidik. Tek. Mesin Undiksha, vol. 6, no. 1, 2018, doi: 10.23887/jjtm.v6i1.11510.

[12] G. Aditya and D. Darlis, "PERANCANGAN DYNOTEST PORTABLE UNTUK SEPEDA MOTOR DENGAN SISTEM MONITORING MENGGUNAKAN MODUL ISM FREKUENSI 2 . 4 GHz DYNOTEST POTABLE DESIGN FOR MOTORCYCLE WITH MONITORING SYSTEM USING ISM MODULE FREQUENCY 2 . 4 GHZ," e-Proceeding Appl. Sci., vol. 1, no. 2, pp. 1231-1238, 2015.

[13] I. Irwansyah, M. A. Al Banjari, and F. W. Setiawan, "The Effect Of Use Various Types Cables Spark Plugs To 108cc Scooter Machine Performance," JMIO J. Mesin Ind. dan Otomotif, vol. 2, no. 01, 2021, doi: 10.46365/jmio.v2i01.405.

[14] O. M. Ali, "Utilisation of Chemical Waste Additives with Low Octane Commercial Gasoline Fuel to Enhance the Performance of SI Engines," Int. J. Automot. Mech. Eng., vol. 18, no. 1, 
Analisis Variasi Busi Terhadap Performa dan Bahan Bakar Motor Bensin 2 Langkah Yamaha F1ZR 110CC

2021, doi: 10.15282/ijame.18.1.2021.20.0655.

[15] P. Sementa, F. Catapano, S. Di Iorio, M. Todino, and B. M. Vaglieco, "Analysis of the combustion process of si engines equipped with non-conventional ignition system architecture," in SAE Technical Papers, 2020, vol. 2020-June, no. June, doi: 10.4271/2020-370035. 